\title{
Postprandial nutrient-sensing and metabolic responses after partial dietary fishmeal replacement by soyabean meal in turbot (Scophthalmus maximus L.)
}

\author{
Dandan Xu, Gen He*, Kangsen Mai, Huihui Zhou, Wei Xu and Fei Song \\ The Key Laboratory of Aquanutrition, Ocean University of China, Qingdao 266003, People's Republic of China \\ (Submitted 13 February 2015 - Final revision received 10 October 2015 - Accepted 15 October 2015 - First published online 20 November 2015)
}

\section{Abstract}

In this study, we chose a carnivorous fish, turbot (Scophthalmus maximus L.), to examine its nutrient-sensing and metabolic responses after ingestion of diets with fishmeal (FM), or $45 \%$ of FM replaced by soyabean meal ( $34.6 \%$ dry diet) balanced with or without essential amino acids (EAA) to match the amino acid profile of FM diet for $30 \mathrm{~d}$. After a 1-month feeding trial, fish growth, feed efficiency and nutrient retention were markedly reduced by soyabean meal-incorporated (SMI) diets. Compared with the FM diet, SMI led to a reduction of postprandial influx of free amino acids, hypoactivated target of rapamycin signalling and a hyperactivated amino acid response pathway after refeeding, a status associated with reduced protein synthesis, impaired postprandial glycolysis and lipogenesis. These differential effects were not ameliorated by matching an EAA profile of soyabean meal to that of the FM diet through dietary amino acid supplementation. Therefore, this study demonstrated that the FM diet and SMI diets led to distinct nutrient-sensing responses, which in turn modulated metabolism and determined the utilisation efficiency of diets. Our results provide a new molecular explanation for the role of nutrient sensing in the inferior performance of aquafeeds in which FM is replaced by soyabean meal.

Key words: Fishmeal: Soyabean meal: Turbot: Nutrient sensing: Metabolism

With the rapid growth of aquaculture, demand for aquafeed with less fishmeal (FM) has increased because of the cost of this protein source and its limited supply ${ }^{(1)}$. During the past decade, considerable progress has been made towards replacing portions of FM in aquafeeds with alternative protein sources ${ }^{(1,2)}$. Currently, FM is becoming a minor protein source in the feed for omnivorous species. However, it continues to be the primary protein source in aquafeed for marine species and other species during the fry or fingerling stage ${ }^{(2)}$. The oversubstitution of FM has generally led to reduced growth performance in marine carnivorous species ${ }^{(1,2)}$. The inferior performance of non-FM protein sources (plant proteins, in particular) has been attributed to nutritional limitations, such as the imbalanced amino acid profiles, presence of anti-nutritional compounds and other factors ${ }^{(2)}$. However, little is known regarding the nutrient-sensing and metabolic changes after FM replacement in aquatic animals.

Postprandial responses represent a critical step towards defining the utilisation efficiency of dietary protein sources ${ }^{(3,4)}$. Feeding-induced stimulation of anabolic protein synthesis depends on postprandial repletion of amino acid pools in plasma and other tissues ${ }^{(5)}$. Mediated by amino acid transporters, amino acid availability in turn mediates the activation of nutrient-sensing cascades, including target of rapamycin (TOR) and amino acid response (AAR) pathways, both of which control protein synthesis and downstream metabolism ${ }^{(6)}$. The activated TOR signalling pathway promotes the translation of many anabolic enzymes and other proteins involved in diverse cellular functions ${ }^{(7-9)}$. However, any individual amino acid limitation can activate the AAR pathway, which triggers global protein synthesis repression and induces translation of rate-limiting enzymes related to amino acid and lipid metabolism ${ }^{(10,11)}$. The counter-regulatory mechanisms of amino acid sensing exist to coordinate the action of TOR and AAR pathways and their downstream effects on translation, which provide the molecular basis for nutritional responses ${ }^{(12)}$.

Most nutrient-sensing studies in fish focus on cellular responses in vitro ${ }^{(13-15)}$. However, such information may not provide important explanations concerning the physiological responses generated by a certain protein source in animals. We hypothesised that dietary FM replacement would probably change the postprandial nutritional response of fish, which, in turn, would have an impact on their metabolism and phenotypic performance. To test this hypothesis, an economically valuable marine carnivorous fish species, turbot (Scophthalmus maximus L.),

Abbreviations: AAR; amino acid response; $B^{O} A T 1 ; \mathrm{B}^{0}$-type amino acid transporter 1 ; EAA; essential amino acids; eIF2 $\alpha$; eukaryotic initiation factor $2 \alpha$. FM; fishmeal; PepT1; peptide transporter 1; S6; ribosomal protein S6; SMI; soyabean meal-incorporated diet; SMI + AA; SMI diet with dietary EAA supplementation; SNAT2; sodium-coupled neutral amino acid transporter 2; TOR; target of rapamycin; $y^{+} L A T 1 ; \mathrm{y}^{+} \mathrm{L}$-type amino acid transporter 1.

* Corresponding author: G. He, fax +86 5328203 1627, email hegen@ouc.edu.cn 
was chosen as the model species because of its high dietary protein requirement ${ }^{(16)}$. Fish were fed either an FM diet or partial FM replacement by soyabean meal with or without essential amino acid (EAA) supplementation diets, which represented the most frequently used strategy for improving the performance of non-FM proteins ${ }^{(17)}$. After the feeding trial, a comprehensive characterisation of the postprandial dynamics of the expression of amino acid transporters, free amino acid pools, the activation of nutrient-sensing molecules and the regulated expression of key metabolic enzymes was evaluated. Our results could contribute to mechanistic explanations on the performance changes after FM replacement in mariculture.

\section{Methods \\ Diets}

The ingredients and composition of the experimental diets are shown in Table 1. Their amino acid profiles are shown in online Supplementary Table S1. Turbot were fed with three isonitrogenous $(50 \cdot 1 \%$ crude protein) and isoenergetic $(20.8 \mathrm{~kJ} / \mathrm{g})$ diets comprising different protein sources (Table 1): $60 \% \mathrm{FM}$ and $33 \% \mathrm{FM}+34.6 \%$ soyabean meal ( $45 \%$ FM replaced with soyabean meal) incorporated (SMI) without or with (SMI diet with dietary EAA supplementation (SMI + AA)) amino acids supplemented to match the EAA profile of the FM diet. The ingredients were ground into a fine powder through a $320-\mu \mathrm{m}$ mesh. All of the ingredients were thoroughly mixed and extruded as pellets, dried at $45^{\circ} \mathrm{C}$ for $12 \mathrm{~h}$, sieved and refrigerated at $-20^{\circ} \mathrm{C}$ before feeding.

\section{Feeding trial and sampling}

All experimental protocols were approved by the Animal Care Committee of Ocean University of China. Juvenile turbot were obtained from Haiyang fish farm (Haiyang, China). During the acclimatisation period, fish were fed a commercial diet (Great Seven Bio-tech) twice per day, for 2 weeks. To start the experiment, the juvenile turbot with an initial weight of 9.19 (SEM 0.01) g were randomly distributed into tanks filled with 500 litres of seawater, with forty fish in each tank. Diets were randomly allocated in triplicate to the tanks. Fish were fed twice per day, until apparent satiation, for $30 \mathrm{~d}$. During the experimental period, the water temperature was $16-20^{\circ} \mathrm{C}$. The uneaten feed was collected $1 \mathrm{~h}$ after each meal, dried to a constant weight and weighed to allow calculation of food intake.

Before the feeding trial, twenty fish from the same population were randomly collected for initial biochemical analysis. At the end of the feeding trial, fish were fasted for $48 \mathrm{~h}$ to obtain the basal levels of metabolites in fish ${ }^{(18)}$. After $24 \mathrm{~h}$ of fasting, fish in each tank were weighed and counted, and four fish per tank were randomly selected for biochemical analysis. At the end of the 48-h fasting period, the sampled fish were designated as the 0 -h sample (fasted fish). The fish were then fed a single meal of their allocated diet until visible satiation. Samples were collected at 2-, 8- and 24-h intervals after refeeding. At each interval, six fish (two fish per tank) were randomly taken from every treatment $(n$ 6). Fish were anaesthetised with benzocaine
Table 1. Formulations of experimental diets

\begin{tabular}{|c|c|c|c|}
\hline & \multicolumn{3}{|c|}{ Diets (\% dry weight) } \\
\hline & FM & SMI & $\mathrm{SMI}+\mathrm{AA}$ \\
\hline \multicolumn{4}{|l|}{ Ingredients (\%) } \\
\hline Fishmeal $^{\star}$ & $60 \cdot 0$ & 33.0 & 33.0 \\
\hline Soyabean meal† & 0 & 34.6 & 34.6 \\
\hline Wheat gluten meal & 3.0 & $5 \cdot 0$ & 3.5 \\
\hline Wheat mealf & $23 \cdot 6$ & $12 \cdot 0$ & $12 \cdot 0$ \\
\hline Fish oil & 3.0 & $5 \cdot 0$ & $5 \cdot 0$ \\
\hline Palm oil & 1.5 & 0.5 & 0.5 \\
\hline Lecithin & 2.5 & 2.5 & 2.5 \\
\hline Mineral premix§ & 1.5 & 1.5 & 1.5 \\
\hline Vitamin premix\| & 1.5 & 1.5 & 1.5 \\
\hline $\mathrm{Ca}\left(\mathrm{H}_{2} \mathrm{PO}_{4}\right)_{2} \cdot \mathrm{H}_{2} \mathrm{O}$ & 0 & 1.0 & 1.0 \\
\hline Amino acid mixturef & 0 & 0 & 1.5 \\
\hline Others** & 3.4 & 3.4 & 3.4 \\
\hline \multicolumn{4}{|c|}{ Analytical composition (DM basis) } \\
\hline DM (\%) & 95.0 & 94.8 & $95 \cdot 1$ \\
\hline Crude protein (\%) & $50 \cdot 1$ & $50 \cdot 3$ & 49.9 \\
\hline Crude lipid (\%) & 11.6 & 11.4 & $11 \cdot 2$ \\
\hline Ash (\%) & 13.4 & 11.4 & 11.2 \\
\hline Gross energy $(\mathrm{kJ} / \mathrm{g})$ & 20.7 & $20 \cdot 8$ & 21.0 \\
\hline
\end{tabular}

FM, fishmeal; SMI, soyabean meal-incorporated diet; SMI + AA, SMI diet with dietary essential amino acid supplementation.

${ }^{*}$ FM: steam-dried FM (Copeinca Group), with crude protein: $70 \cdot 10 \%$, crude lipid: $7.58 \%$.

† Soyabean meal: dehulled, solvent-extracted soyabean meal (Great Seven Bio-tech), with crude protein: $54 \cdot 61 \%$, crude lipid: $2.33 \%$.

¥ Wheat meal and wheat gluten meal act as a carbohydrate source and as a filler (Great Seven Bio-tech)

$\S$ Mineral premix (mg/kg diet): $\mathrm{CoCl}_{2} \cdot 6 \mathrm{H}_{2} \mathrm{O}(1 \%), 50 ; \mathrm{CuSO}_{4} \cdot 5 \mathrm{H}_{2} \mathrm{O}(25 \%), 10$; $\mathrm{FeSO}_{4} \cdot \mathrm{H}_{2} \mathrm{O}(30 \%), 80 ; \mathrm{ZnSO}_{4} \cdot \mathrm{H}_{2} \mathrm{O}(34.50 \%), 50 ; \mathrm{MnSO}_{4} \cdot \mathrm{H}_{2} \mathrm{O}(31.80 \%), 45$; $\mathrm{MgSO}_{4} .7 \mathrm{H}_{2} \mathrm{O}(15 \%), 1200$; sodium selenite (1\%), 20 ; calcium iodine (1\%) 60 ; zeolite, 11470 .

॥ Vitamin premix (mg/kg diet): thiamin (98\%), 25; riboflavin (80\%), 45; pyridoxine- $\mathrm{HCl}$ $(99 \%), 20$; vitamin $\mathrm{B}_{12}(1 \%), 10$; vitamin $\mathrm{K}_{3}(51 \%)$, 10; inositol $(98 \%), 800$; pantothenic acid (98\%), 60; niacin acid (99\%), 200; folic acid (98\%), 20; biotin $(2 \%), 60$; retinyl acetate $(15 \%), 32$; cholecalciferol $(1.25 \%), 5$; $a$-tocopherol $(50 \%), 240$; ascorbic acid (35\%), 2000; antioxidants (oxygen ling grams, $100 \%), 3$; rice husk powder (100\%), 11470

I Amino acid mixture: L-lysine (coated amino acid, $60 \%$ ) $0.6 \%$, L-methionine (coated amino acid obtained, $90 \%$ ) $0.32 \%$, L-isoleucine (crystalline amino acid, $99.4 \%$ ) $0.12 \%$, L-leucine (crystalline amino acid, 99.4) $0.13 \%$, L-threonine (crystalline amino acid, $99.9 \%$ ) $0.13 \%$, L-valine (crystalline amino acid, 99.1\%) $0.16 \%$. Coated amino acid was obtained from Beijing XingHuo Yuan Science and Technology Co. Ltd and crystalline amino acid was obtained from Jizhou City Huayang Chemical Co. Ltd.

** Others: beer yeast $2 \%$, choline chloride $0.25 \%$, mould inhibitor $0.1 \%$, antioxidant $0.05 \%$, attractant (betaine-dimethylpropiothetin-glycine-alanine-inosine 5'-phosphate $=4: 2: 2: 1: 1) 1.0 \%$

(30 mg/l) and killed by cervical section. The stomach and gut contents of each fish were checked to ensure that the fish had effectively consumed the diet. The liver, intestine and dorsolateral white muscle were immediately dissected and frozen in liquid $\mathrm{N}_{2}$ and kept at $-80^{\circ} \mathrm{C}$. The other six fish in each treatment were selected, anaesthetised, visually checked as to whether or not the belly was bulging greatly because of a full diet in the digestive tract and blood was extracted from the caudal vein into heparin anti-coagulation tubes and centrifuged at $3000 \boldsymbol{g}$ for $5 \mathrm{~min}$. The recovered plasma was kept at $-80^{\circ} \mathrm{C}$ until analysis.

\section{Biochemical analysis}

$\mathrm{DM}\left(105^{\circ} \mathrm{C}\right.$ for $\left.24 \mathrm{~h}\right)$, crude protein $(\mathrm{N} \times 6.25$, Kjeltec nitrogen analyser $^{\mathrm{TM}}$ 8400; FOSS), crude lipid (ether extraction, Soxhlet method) and ash (combustion in a muffle furnace at $550^{\circ} \mathrm{C}$ for $12 \mathrm{~h}$ ) 
Table 2. Primer sequences used for real-time quantitative PCR*

\begin{tabular}{|c|c|c|c|}
\hline Genes† & Forward prime & Reverse primer & Product size (bp) \\
\hline \multicolumn{4}{|c|}{ Peptide and amino acid transporters } \\
\hline PepT1 & GCATCCACACCCAGCAGAAG & GTCCTCAGCCCAGTCCATCC & 232 \\
\hline$B^{\circ} A T 1$ & AGACTCTCAACACCTCCGAAGC & AGCCTTTCCTGTGGTCTCAATCC & 131 \\
\hline$y^{+} L A T 1$ & TGTGACGTTTGCGGACCAG & GACGGGAGTGTAGCGGAAGAC & 186 \\
\hline SNAT2 & TGCTGCTGGTGACGCTCTTC & CAGGTGTCCTCGCTGTAGTCC & 249 \\
\hline \multicolumn{4}{|c|}{ Key enzymes of nutrient metabolism } \\
\hline GK & CGACACGAGGACATTGACAAG & CCAACAATCATCCCGACTTCAC & 218 \\
\hline PK & TGGATACGCTGAAGGAGATG & ACGCACGTTCTTGATGGTC & 236 \\
\hline FBPase & CAGGAAGGCTGGGATCGCTAAC & СТСАТСTTCСТCCGACACAAG & 157 \\
\hline G6Pase & CACGAGACGGCTCATTATGC & CTTTGCTGCTGGATTTCTTGC & 193 \\
\hline SREBP1 & GCCATTGACTACATCCGTTAC & CATCAGCCTGTCCATCTACTTC & 136 \\
\hline FAS & GGCAACAACACGGATGGATAC & CTCGCTTTGATTGACAGAACAC & 195 \\
\hline DGAT1 & ATACTCGTGTCCATCTGTGTCTC & AGTCGTCTCATCAGGAACCTTAC & 177 \\
\hline DGAT2 & TGCTGTGGTCATCGTTATC & CTTGTAGGCGTCGTTCTC & 163 \\
\hline CPT1A & ATGGGAAGAGTGGACTGAATG & GCTGGAAGGCATCTGTGG & 96 \\
\hline ACOX1 & AGTCCTCGCCCAGCTTTACT & GGCTTCACATAGGTTCCGTCT & 240 \\
\hline \multicolumn{4}{|c|}{ Reference genes } \\
\hline RPSD & CTGCTGTTCCCTAAAGAGTTCG & GAGCCGTGTAGTTCAGGGTCT & 151 \\
\hline EF1a & TCATTGGCCATGTCGACTCC & ACGTAGTACTTGGCGGTCTC & 226 \\
\hline
\end{tabular}

* Abbreviations and GenBank accession nos: ACOX1, acyl-CoA oxidase 1, KC189925; CPT1A, carnitine palmitoyltransferase 1 isoforms A, KC189926; DGAT1, diacylglycerol O-acyltransferase homolog 1, KC189938; DGAT2, diacylglycerol O-acyltransferase homolog 1, KC189939; EF1a, elongation factor-1 a, AF467776.1; FAS, fatty acid synthase, KC189927; FBPase, fructose 1,6-bisphosphatase, KC184130; G6Pase, glucose 6 phosphatase, KC184131; GK, glucokinase, JX678944; PK, pyruvate kinase, DQ848903; $R P S D$, RNA polymerase II subunit D, DQ848899.1; partial sequences of some target genes in turbot were obtained through a degenerate PCR strategy in this study, including $B^{O} A T 1, B^{0}$-type amino acid transporter 1; PepT1, peptide transporter 1; SNAT2, sodium-coupled neutral amino acid transporter 2; SREBP1, sterol regulatory element-binding

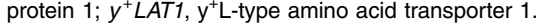

† For the nucleotide sequences of genes $B^{O} A T 1$, PepT1, SNAT2, SREBP1 and $y^{+} L A T 1$, see the online Supplementary material.

of the experimental diets and fish samples were analysed as described elsewhere ${ }^{(19)}$. The gross energies of feed and fish samples were measured using an adiabatic bomb calorimeter (C2000; Ika Werke). Amino acids in ingredients and diets were analysed using an amino acid analyzer (L-8900; Hitachi). Plasma glucose (GLU) and TAG concentrations were measured using commercial kits according to the manufacturer's instructions (Sysmex).

\section{Free amino acid analysis}

The postprandial free amino acid concentrations in the plasma and muscle were analysed by an automated amino acid analyser (L-8900) with a lithium high-performance column ${ }^{(20)}$. Briefly, plasma $(400 \mu \mathrm{l})$ was deproteinised by mixing it with $1.2 \mathrm{ml}$ of $10 \%$ sulfosalicylic acid solution and incubating it at $4^{\circ} \mathrm{C}$ for $5 \mathrm{~min}$. After centrifugation at $13000 \mathrm{rpm}$ for $15 \mathrm{~min}, 1 \mathrm{ml}$ of supernatant was filtered through $0 \cdot 22-\mu \mathrm{m}$ filters for free amino acid measurement; in addition, white muscle samples (400 mg) were homogenised in $1.2 \mathrm{ml}$ of $10 \%$ sulfosalicylic acid solution. After centrifugation at $13000 \mathrm{rpm}$ for $15 \mathrm{~min}$, the supernatant was filtered through $0 \cdot 22-\mu \mathrm{m}$ filters for free amino acid measurement.

\section{Quantitative real-time PCR}

Total RNA was extracted from intestine, liver or muscle (approximately $50 \mathrm{mg}$ ) using Trizol reagent (Invitrogen) according to the manufacturer's recommendations, quantified by a Nanodrop 2000 spectrophotometer (Thermo) and electrophoresed on a $1.2 \%$ denaturing agarose gel to test the integrity. complementary DNA synthesis and quantitative real-time PCR (qRT-PCR) reactions were conducted as described previously ${ }^{(21)}$. Specific primer sequences of target genes for qRT-PCR are listed in Table 2. qRT-PCR analyses were focused on the postprandial kinetics of peptide and amino acid transporters, which were peptide transporter 1 (PepT1) mediating the uptake of essentially all dipeptides and tripeptides ${ }^{(22)}$; $\mathrm{B}^{0}$-type amino acid transporter $1\left(B^{O} A T 1\right)$ transporting all neutral amino acids; sodium-coupled neutral amino acid transporter 2 (SNAT2) preferring alanine and other small and polar neutral amino acids; and $\mathrm{y}^{+} \mathrm{L}$-type amino acid transporter $1\left(y^{+} L A T 1\right)$ mediating the transport of cationic amino acids ${ }^{(23)}$. We also examined the gene expression of several key enzymes of hepatic metabolism, which were as follows: glucokinase $(G K)$ and pyruvate kinase $(P K)$ for glycolysis; fructose 1,6-bisphosphatase (FBPase) and glucose 6 phosphatase (G6Pase) for gluconeogenesis; transcription factor sterol regulatory element-binding protein 1 (SREBP1) and fatty acid synthase $(F A S)$ for fatty acid synthesis; diacylglycerol O-acyltransferase homolog (DGAT) 1 and DGAT2 for TAG synthesis; and carnitine palmitoyltransferase 1 isoforms $\mathrm{A}(C P T 1 A)$ and acyl-CoA oxidase 1 (ACOX1) for fatty acid oxidation ${ }^{(13,24)}$. Results were normalised to reference genes RNA polymerase II subunit D (RPSD) for intestine and muscle samples, and elongation factor $1 \alpha$ (EF1 $\alpha$ ) for liver samples. No expression changes of RPSD and EF1 $\alpha$ were observed in the corresponding tissues among treatments (online Supplementary Fig. S1). The expression levels of target mRNA were calculated using the comparative cycle threshold $\left(C_{t}\right)$ values expressed as $2^{\left(-\Delta \Delta C_{t}\right)}$. Transcription levels were normalised by the reference gene. Gene expression was represented as fold change to the control ( $\mathrm{T} 0 \mathrm{~h}$ FM).

\section{Protein extraction and Western blot analysis}

Tissues (approximately $40 \mathrm{mg}$ ) were homogenised with Glass Tenbroeck Tissue Grinders (Kimble Chase) on ice and lysed in 
Table 3. Growth performance and nutrient utilisation of turbot after 30-d diet feeding trial (Mean values with their standard errors; $n 3$ )

\begin{tabular}{|c|c|c|c|c|c|c|c|}
\hline & \multicolumn{2}{|c|}{ FM } & \multicolumn{2}{|c|}{ SMI } & \multicolumn{2}{|c|}{$\mathrm{SMI}+\mathrm{AA}$} & \multirow[b]{2}{*}{$P$} \\
\hline & Mean & SE & Mean & SE & Mean & SE & \\
\hline Initial body weight (g) & $9 \cdot 2$ & 0.01 & $9 \cdot 2$ & 0.01 & $9 \cdot 2$ & 0.01 & 0.95 \\
\hline Final body weight $(\mathrm{g})$ & $28 \cdot 8^{\mathrm{a}}$ & 1.01 & $21 \cdot 4^{\mathrm{b}}$ & 0.13 & $23 \cdot 3^{b}$ & 0.22 & $<0.001$ \\
\hline Specific growth rate $(\% / d)^{*}$ & $3 \cdot 3^{a}$ & $0 \cdot 10$ & $2 \cdot 4^{\mathrm{b}}$ & 0.02 & $2 \cdot 6^{\mathrm{b}}$ & 0.03 & $<0.001$ \\
\hline Feed intake $(\% / d) \dagger$ & $2 \cdot 3$ & 0.13 & $2 \cdot 2$ & 0.05 & $2 \cdot 2$ & 0.05 & 0.64 \\
\hline Feed efficiency $\ddagger$ & $1.5^{\mathrm{a}}$ & 0.06 & $1 \cdot 2^{b}$ & 0.04 & $1 \cdot 3^{b}$ & 0.02 & 0.01 \\
\hline Protein retention $(\%) \S$ & $48 \cdot 1^{\mathrm{a}}$ & 1.94 & $39 \cdot 6^{b}$ & 0.64 & $40.5^{\mathrm{b}}$ & 0.40 & 0.004 \\
\hline Fat retention $(\%) \S$ & $53 \cdot 8^{\mathrm{a}}$ & $2 \cdot 30$ & $34 \cdot 4^{\mathrm{b}}$ & 1.34 & $29 \cdot 4^{\mathrm{b}}$ & 1.42 & 0.001 \\
\hline Energy retention $(\%) \S$ & $36 \cdot 6^{a}$ & 1.45 & $27 \cdot 7^{\mathrm{b}}$ & 1.21 & $27 \cdot 1^{\mathrm{b}}$ & 1.44 & 0.004 \\
\hline Whole-body protein content (\% wet weight) & $15 \cdot 4$ & 0.14 & $15 \cdot 4$ & 0.28 & 14.9 & 0.18 & 0.21 \\
\hline Whole-body fat content (\% wet weight) & $3.5^{\mathrm{a}}$ & $0 \cdot 17$ & $2 \cdot 7^{\mathrm{b}}$ & 0.04 & $2 \cdot 3^{b}$ & 0.09 & 0.001 \\
\hline Percentage of survivalll & 100 & & 100 & & 98.3 & 2.89 & 0.42 \\
\hline
\end{tabular}

FM, fishmeal diet; SMI, soyabean meal-incorporated diet; SMI + AA, SMI diet with dietary essential amino acids supplementation.

a,b Mean values within a row with unlike superscript letters were significantly different $(P<0.05)$.

* Specific growth rate $(\% / \mathrm{d})=100 \times($ In final body weight - In initial body weight $) / \mathrm{d}$.

$\dagger$ Feed intake $(\%$ body weight $/ \mathrm{d})=100 \times$ feed consumption/( $30 \mathrm{~d} \times($ initial body weight + final body weight $) / 2)$.

$\ddagger$ Feed efficiency $=$ wet weight gain $(\mathrm{g}) /$ total feed consumed $(\mathrm{g})$.

$\S$ Nutrient retention $=(100 \times($ final body weight $\times$ final carcass nutrient content $)-($ initial body weight $\times$ initial carcass nutrient content $) /$ nutrient intake, where nutrient refers to protein,

lipid and energy.

॥ Percentage survival $=100 \times$ (final fish number/initial fish number).

radioimmunoprecipitation assay buffer $(50 \mathrm{~mm}$-Tris, $150 \mathrm{~mm}-\mathrm{NaCl}$, $0.5 \%$ Nonidet P-40, $0.1 \%$ SDS, 1 mm-EDTA, pH 7.5) with protease and phosphatase inhibitors (Roche). Lysates were centrifuged at $12000 \mathrm{~g}$ for $20 \mathrm{~min}$ at $4^{\circ} \mathrm{C}$. Protein concentrations were determined using an Enhanced BCA Protein Assay Kit (Beyotime Biotechnology) with bovine serum albumin as standard. Lysates (10 $\mu \mathrm{g}$ of total protein/lane) were separated by SDS-PAGE and transferred to $0 \cdot 45-\mu \mathrm{m}$ polyvinylidene fluoride membranes (Millipore) for Western blot analysis. Primary antibodies against phospho-Akt (Ser473) (Cat. no. 9271), Akt (Cat. no. 9272), phospho-TOR (Ser2448) (Cat. no. 2971), TOR (Cat. no. 2972), phospho-S6 (Ser235/236) (Cat. no. 4856), S6 (Cat. no. 2217), phospho-4E-BP1 (Thr37/46) (Cat. no. 9459), 4E-BP1 (Cat. no. 9452), phospho-eIF2 $\alpha$ (Ser51) (Cat. no. 3597) and eIF $2 \alpha$ (Cat. no. 9722) were purchased from Cell Signaling Technology Inc. Anti-ATF4 antibody (Cat. no. sc-200) was purchased from Santa Cruz Biotechnology Inc. All antigenic regions of these antibodies have been reported as conserved in turbot ${ }^{(25)}$, and also successfully used in rainbow trout in previous studies ${ }^{(18,26)}$. Next, membranes were incubated with HRP-labelled goat anti-rabbit IgG ( $\mathrm{H}+\mathrm{L})$ second antibody (Beyotime Biotechnology), and developed using a Beyo ECL Plus kit (Beyotime Biotechnology). The density of protein bands was quantified using the NIH Image 1.63 software $(n 6)$.

\section{Statistical analysis}

The SPSS 16.0 software was used for all statistical analysis. The data of growth performance were subjected to one-way ANOVA, followed by Tukey's multiple range tests. The data for the time course and different diets were analysed by two-way ANOVA, testing the main effects of time (T) and diet (D), and their fullfactorial interaction. Tukey's multiple range tests were conducted in order to detect treatment differences among the interactions.
In cases in which data were nonparametric or not homoscedastic, data transformations (such as logarithms, square roots and reciprocals) were used to meet ANOVA criteria. Normality was assessed using the Shapiro-Wilks' test, whereas homoscedasticity was determined using Levene's test. For all statistical analyses, the level of significance was set at $P<0.05$.

\section{Results}

\section{Phenotypic characterisation of dietary performance}

After the 1-month feeding trial, no significant differences were found for feed intake, whole-body protein content or percentage survival for all treatments (Table 3). Compared with the FM diet, two SMI diets (SMI and SMI + AA) resulted in decreased specific growth rate $(P<0.001)$, feed efficiency $(P=0.01)$, protein $(P=0.004)$, fat $(P=0.001)$ and energy $(P=0.004)$ retention, and whole-body fat content $(P=0.001)$ (Table 3$)$. No significant differences were found between the SMI and $\mathrm{SMI}+\mathrm{AA}$ diets for any of these measures.

\section{Postprandial modulations of amino acid transporters by dietary proteins}

Postprandial gene expressions of major amino acid transporters in the intestine were measured (Fig. 1). After refeeding, the expression levels of intestinal PepT1 and $y^{+}$LAT1 were significantly increased and peaked at 2 and $8 \mathrm{~h}$, respectively, whereas the mRNA levels of $B^{O} A T 1$ and SNAT2 were markedly decreased (Fig. 1). Compared with the FM diet, SMI and SMI + AA diets did not significantly influence the postprandial gene expressions of PepT1 or SNAT2. However, the SMI diet significantly decreased the peak level of $y^{+} L A T 1$ and reduction of $B^{O} A T 1$ after refeeding in the intestine (Fig. 1). Supplementation of EAA to the SMI diet significantly shifted the postprandial gene expression pattern of 

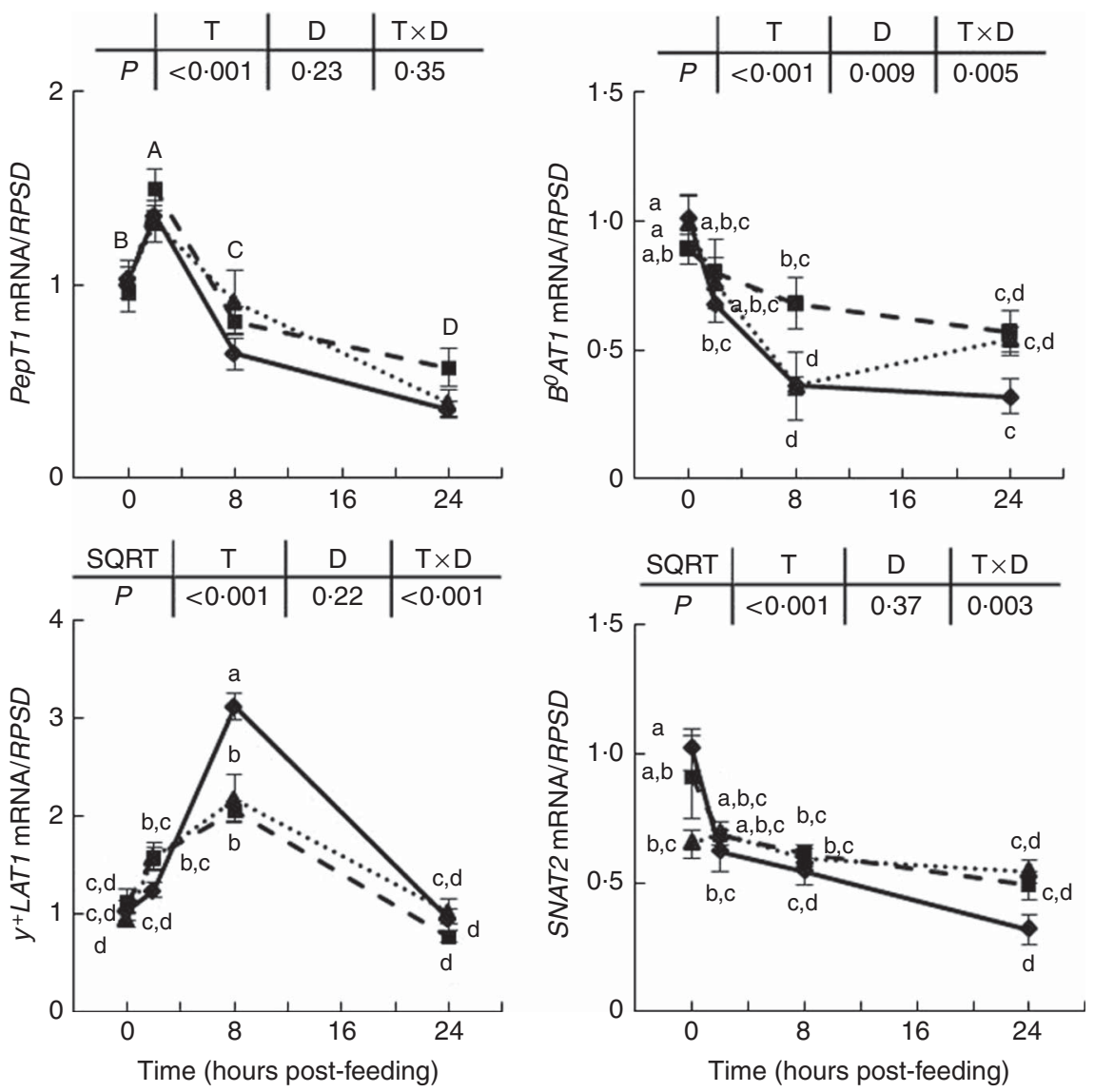

Fig. 1. Postprandial expressions of peptide and amino acid transporters in intestine of juvenile turbot. Values are means ( $n$ 6), with their standard errors and were analysed by two-way ANOVA followed by Tukey's multiple range test. ${ }^{a, b, c, d}$ Mean values among all treatments with unlike letters are significantly different when the interaction was significant $(P<0.05)$. ${ }^{\mathrm{A}, \mathrm{B}, \mathrm{C}, \mathrm{D}}$ Mean values among four time points with unlike letters were significantly different $(P<0.05)$. T, time points; $\mathrm{D}$, diets; T $\times \mathrm{D}$, interaction between Tand D; fishmeal diet (—); SMI, soyabean meal-incorporated diet ( $-\square)$; soyabean meal-incorporated diet with dietary essential amino acids supplementation (......); SQRT indicates that data were transformed and statistically analysed with square roots; $B^{\circ} A T 1$, $\mathrm{B}^{0}$-type amino acid transporter 1 ; PepT1, peptide transporter 1; SNAT2, sodium-coupled neutral amino acid transporter $2 ; y^{+} L A T 1, \mathrm{y}^{+} L$-type amino acid transporter 1 ; RPSD, RNA polymerase II subunit D.

$B^{O} A T 1$ to that of the FM diet, but it showed no significant impact on postprandial peak values of $y^{+} L A T 1$ (Fig. 1).

\section{Postprandial free amino acid influx was modulated by dietary proteins}

The postprandial kinetics of the free amino acid concentrations in plasma and muscle are shown in Tables 4 and 5, and in online Supplementary Tables S2 and S3. Plasma free amino acid concentrations were markedly increased and peaked $2-8 \mathrm{~h}$ after refeeding, before returning to basal levels. Compared with the FM diet, the SMI diet provided significantly lower free amino acids entering into plasma, whereas dietary EAA supplementation fully compensated for these deficits (Table 4 and online Supplementary Table S2). Postprandial free amino acid concentrations in muscle were markedly increased and peaked $8 \mathrm{~h}$ after refeeding. The SMI diet led to significantly reduced postprandial peak values of free amino acids and shorter duration of total EAA concentrations in muscle. EAA supplementation in the SMI diet did not significantly affect postprandial peak values of the majority of free amino acids in muscle (Table 5 and online Supplementary Table S3).
Postprandial modulations of amino acid-sensing pathways by dietary proteins

Postprandial activation of amino acid-sensing pathways was examined in muscle (Fig. 2(A)) and liver (Fig. 2(B)). Two-way ANOVA statistical analysis showed that the phosphorylation of TOR and AAR pathways were both significantly affected by refeeding time courses and different diets $(P<0 \cdot 01)$. The TOR pathway was markedly activated by refeeding both in muscle and liver, characterised by the phosphorylation of protein kinase B (Akt) on Ser473, TOR on Ser2448, ribosomal protein S6 (S6) on Ser235/236 and eukaryotic initiation factor 4E-binding protein 1 (4E-BP1) on Thr37/46 (Fig. 2). Contrarily, the AAR-related molecule eukaryotic initiation factor $2 \alpha(\mathrm{eIF} 2 \alpha)$ on Ser51 was markedly activated during starvation (time $0 \mathrm{~h}$ ) and inhibited after refeeding in all three diets. Compared with the FM diet, the SMI diet led to significantly lower levels and shorter duration of phosphorylation of Akt, TOR, S6 and 4E-BP1 in both muscle and liver tissues (Fig. 2). However, the SMI diet significantly induced stress-responsive eIF $2 \alpha$ phosphorylation and activating transcription factor 4 (ATF4) (Fig. 2). Supplementation of EAA to the soyabean diet did not have a 
Table 4. Changes of plasma individual free essential amino acid (EAA) concentrations in turbot after refeeding $(\mu \mathrm{g} / \mu \mathrm{l})$ (Pooled standard errors)

\begin{tabular}{|c|c|c|c|c|c|c|c|c|c|c|c|c|}
\hline Diets & $\mathrm{T}(\mathrm{h})$ & Leu & Ile & Val & Thr & Met & Phe & Lys & His & Arg & EAA & TAA \\
\hline \multicolumn{13}{|c|}{ Individual treatment means ${ }^{*}$} \\
\hline FM & 0 & $13 \cdot 3$ & $8 \cdot 3^{f}$ & $9 \cdot 3^{d}$ & $10 \cdot 0^{\mathrm{e}}$ & $5 \cdot 6^{f}$ & 5.4 & $14 \cdot 2$ & $4 \cdot 1$ & $5 \cdot 7$ & $75 \cdot 9^{\dagger}$ & $161 \cdot 8$ \\
\hline FM & 2 & 58.9 & $28 \cdot 6^{a, b}$ & $42 \cdot 2^{a, b}$ & $25 \cdot 5^{\mathrm{a}}$ & $18 \cdot 6^{\mathrm{c}, \mathrm{d}}$ & 23.7 & $30 \cdot 1$ & $9 \cdot 0$ & $36 \cdot 8$ & $273 \cdot 4^{\mathrm{a}, \mathrm{b}}$ & $469 \cdot 4$ \\
\hline FM & 8 & 69.0 & $31 \cdot 1^{\mathrm{a}}$ & $53 \cdot 9^{\mathrm{a}}$ & $27 \cdot 4^{\mathrm{a}}$ & $27 \cdot 4^{\mathrm{b}}$ & $35 \cdot 2$ & $23 \cdot 9$ & $8 \cdot 7$ & $28 \cdot 6$ & $305 \cdot 2^{\mathrm{a}}$ & $485 \cdot 9$ \\
\hline FM & 24 & 33.0 & $18 \cdot 5^{\mathrm{c}, \mathrm{d}, \mathrm{e}}$ & $20 \cdot 7^{\mathrm{c}, \mathrm{d}}$ & $19 \cdot 9^{\mathrm{a}, \mathrm{b}, \mathrm{c}}$ & $9 \cdot 8^{\mathrm{e}, \mathrm{f}, \mathrm{g}}$ & $19 \cdot 6$ & 18.9 & $6 \cdot 2$ & $12 \cdot 6$ & $159 \cdot 2^{\mathrm{c}, \mathrm{d}, \mathrm{e}}$ & $248 \cdot 2$ \\
\hline SMI & 0 & $17 \cdot 3$ & $10 \cdot 4^{\mathrm{d}, \mathrm{e}, \mathrm{f}}$ & $14 \cdot 7^{d}$ & $9 \cdot 6^{\mathrm{e}}$ & $4 \cdot 9^{\mathrm{h}}$ & 8.0 & $16 \cdot 6$ & $3 \cdot 2$ & $7 \cdot 6$ & $93 \cdot 6^{e, f}$ & $162 \cdot 4$ \\
\hline SMI & 2 & $38 \cdot 1$ & $19 \cdot 5^{\mathrm{b}, \mathrm{c}, \mathrm{d}}$ & $23 \cdot 0^{c, d}$ & $15 \cdot 2^{\mathrm{c}, \mathrm{d}, \mathrm{e}}$ & $10 \cdot 4^{e, f}$ & $22 \cdot 8$ & $20 \cdot 8$ & 7.5 & 33.7 & $190 \cdot 8^{b, c, d}$ & $349 \cdot 1$ \\
\hline SMI & 8 & 49.4 & $26 \cdot 0^{\mathrm{a}, \mathrm{b}, \mathrm{c}}$ & $31.9^{b, c}$ & $17 \cdot 1^{b, c, d}$ & $13 \cdot 3^{\mathrm{d}, \mathrm{e}}$ & $37 \cdot 2$ & 19.5 & $9 \cdot 0$ & $30 \cdot 2$ & $233 \cdot 7^{\mathrm{a}, \mathrm{b}, \mathrm{c}}$ & 369.5 \\
\hline SMI & 24 & $15 \cdot 4$ & $9 \cdot 3^{\mathrm{e}, \mathrm{f}}$ & $12 \cdot 2^{d}$ & $10 \cdot 6^{\mathrm{d}, \mathrm{e}}$ & $5 \cdot 8^{f, g, h}$ & $11 \cdot 1$ & $10 \cdot 5$ & $5 \cdot 9$ & $10 \cdot 8$ & $91 \cdot 6^{\mathrm{e}, \mathrm{f}}$ & $166 \cdot 4$ \\
\hline $\mathrm{SMI}+\mathrm{AA}$ & 0 & $17 \cdot 2$ & $10 \cdot 8^{\mathrm{d}, \mathrm{e}, \mathrm{f}}$ & $14 \cdot 5^{\mathrm{d}}$ & $11 \cdot 5^{\mathrm{d}, \mathrm{e}}$ & $7 \cdot 2^{\mathrm{f}, \mathrm{g}, \mathrm{h}}$ & $9 \cdot 0$ & $16 \cdot 1$ & $4 \cdot 1$ & $9 \cdot 6$ & $99 \cdot 9^{e, f}$ & 173.5 \\
\hline $\mathrm{SMI}+\mathrm{AA}$ & 2 & $51 \cdot 7$ & $28 \cdot 2^{\mathrm{a}, \mathrm{b}, \mathrm{c}}$ & $41 \cdot 8^{\mathrm{a}, \mathrm{b}}$ & $22 \cdot 4^{a, b, c}$ & $24 \cdot 6^{\mathrm{b}, \mathrm{c}}$ & $28 \cdot 1$ & $30 \cdot 3$ & $8 \cdot 8$ & $43 \cdot 6$ & $279 \cdot 3^{\mathrm{a}, \mathrm{b}}$ & 457.5 \\
\hline $\mathrm{SMI}+\mathrm{AA}$ & 8 & $59 \cdot 6$ & $32 \cdot 0^{\mathrm{a}}$ & $55 \cdot 5^{\mathrm{a}}$ & $19 \cdot 9^{\mathrm{a}, \mathrm{b}, \mathrm{c}}$ & $47 \cdot 4^{\mathrm{a}}$ & $43 \cdot 1$ & 29.6 & 8.3 & $37 \cdot 0$ & $332.5^{\mathrm{a}}$ & 489.5 \\
\hline $\mathrm{SMI}+\mathrm{AA}$ & 24 & $20 \cdot 3$ & $11 \cdot 6^{\mathrm{d}, \mathrm{e}, \mathrm{f}}$ & $15 \cdot 6^{c, d}$ & $12 \cdot 0^{\mathrm{d}, \mathrm{e}}$ & $13 \cdot 4^{\mathrm{d}, \mathrm{e}}$ & $15 \cdot 5$ & $15 \cdot 0$ & $6 \cdot 8$ & 11.6 & $121 \cdot 7^{\mathrm{d}, \mathrm{e}, \mathrm{f}}$ & $200 \cdot 2$ \\
\hline Pooled SEM & & $3 \cdot 4$ & $1 \cdot 6$ & $2 \cdot 8$ & $1 \cdot 1$ & $2 \cdot 0$ & $2 \cdot 1$ & 1.2 & 0.4 & $2 \cdot 3$ & $15 \cdot 7$ & $23 \cdot 3$ \\
\hline ANOVA: $P$ & & & & & LG10 & SQRT & & & & SQRT & SQRT & LG10 \\
\hline D & & $<0.001$ & 0.002 & $<0.001$ & $<0.001$ & $<0.001$ & 0.05 & 0.003 & 0.37 & 0.04 & $<0.001$ & $<0.001$ \\
\hline $\mathrm{T}$ & & $<0.001$ & $<0.001$ & $<0.001$ & $<0.001$ & $<0.001$ & $<0.001$ & $<0.001$ & $<0.001$ & $<0.001$ & $<0.001$ & $<0.001$ \\
\hline $\mathrm{D} \times \mathrm{T}$ & & 0.07 & 0.04 & 0.002 & 0.02 & $<0.001$ & 0.14 & $0 \cdot 10$ & 0.79 & 0.69 & 0.03 & 0.15 \\
\hline
\end{tabular}

T, time points; TAA, total free amino acids; FM, fishmeal diet; SMI, soyabean meal-incorporated diet; SMI + AA, SMI diet with dietary EAA supplementation; D, diet; LG10 indicates that data were transformed and statistically analysed with log transforms; SQRT indicates that data were transformed and statistically analysed with square roots.

a,b,c,d,e,f,g,h Mean values among all treatments within a row with unlike superscript letters were significantly different $(P<0.05)$.

* Treatment means represent the average values for three tanks per treatment and were analysed by two-way ANOVA ( $n 3$ ). Tukey's test was conducted for individual means only if there was a significant interaction $(P<0.05)$.

Table 5. Changes of muscle individual free essential amino acid (EAA) concentrations in turbot after refeeding $(\mu \mathrm{g} / \mathrm{g})$ (Pooled standard errors)

\begin{tabular}{|c|c|c|c|c|c|c|c|c|c|c|c|c|}
\hline Diets & $\mathrm{T}(\mathrm{h})$ & Leu & Ile & Val & Thr & Met & Phe & Lys & His & Arg & EAA & TAA \\
\hline \multicolumn{13}{|c|}{ Individual treatment means ${ }^{*}$} \\
\hline FM & 0 & $19 \cdot 0^{\mathrm{e}}$ & $13 \cdot 2^{c}$ & $16 \cdot 9^{\mathrm{c}}$ & $103 \cdot 4^{\mathrm{b}, \mathrm{c}}$ & $8.9^{c}$ & 9.9 & $62 \cdot 8$ & $10 \cdot 7^{c, d}$ & $38 \cdot 3^{c, d, e, f}$ & $279 \cdot 6^{\mathrm{b}, \mathrm{c}}$ & $2506 \cdot 4^{\mathrm{b}, \mathrm{c}}$ \\
\hline FM & 2 & $34.8^{\mathrm{b}}$ & $16 \cdot 5^{\mathrm{a}, \mathrm{b}, \mathrm{c}}$ & $25 \cdot 5^{\mathrm{a}, \mathrm{b}, \mathrm{c}}$ & $80 \cdot 4^{c, d}$ & $13 \cdot 7^{\mathrm{C}}$ & $18 \cdot 8$ & $30 \cdot 7$ & $14 \cdot 7^{\mathrm{c}}$ & $31 \cdot 5^{\mathrm{d}, \mathrm{e}, \mathrm{f}}$ & $266.5^{\mathrm{c}}$ & $2446 \cdot 3^{b, c}$ \\
\hline FM & 8 & $48 \cdot 9^{a}$ & $20 \cdot 6^{\mathrm{b}}$ & $37 \cdot 0^{\mathrm{a}}$ & $128 \cdot 6^{\mathrm{b}}$ & $23 \cdot 4^{\mathrm{b}}$ & $28 \cdot 2$ & $62 \cdot 7$ & $35 \cdot 4^{a}$ & $106 \cdot 3^{a}$ & $491 \cdot 1^{a}$ & $3166 \cdot 7^{\mathrm{a}}$ \\
\hline FM & 24 & $36 \cdot 6^{\mathrm{a}, \mathrm{b}}$ & $21 \cdot 1^{a}$ & $32 \cdot 8^{a, b}$ & $178.5^{\mathrm{a}}$ & $12 \cdot 3^{\mathrm{C}}$ & $23 \cdot 1$ & $126 \cdot 2$ & $35 \cdot 9^{\mathrm{a}}$ & $110 \cdot 9^{a}$ & $577 \cdot 4^{a}$ & $2919 \cdot 4^{\mathrm{a}, \mathrm{b}}$ \\
\hline SMI & 0 & $20 \cdot 5^{\mathrm{d}, \mathrm{e}}$ & $13 \cdot 8^{\mathrm{b}, \mathrm{c}}$ & $21 \cdot 1^{b, c}$ & $61 \cdot 9^{d}$ & $11 \cdot 9^{\mathrm{c}}$ & $10 \cdot 3$ & 49.1 & $7 \cdot 8^{\mathrm{d}}$ & $15 \cdot 8^{\dagger}$ & $212 \cdot 0^{\mathrm{C}}$ & $1830 \cdot 6^{\mathrm{e}}$ \\
\hline SMI & 2 & $31.4^{\mathrm{b}, \mathrm{c}, \mathrm{d}, \mathrm{e}}$ & $16 \cdot 9^{\mathrm{a}, \mathrm{b}, \mathrm{c}}$ & $21 \cdot 3^{b, c}$ & $49 \cdot 7^{d}$ & $8.9^{\mathrm{c}}$ & $17 \cdot 8$ & $21 \cdot 2$ & $11 \cdot 9^{\mathrm{c}, \mathrm{d}}$ & $22 \cdot 5^{\mathrm{e}, \mathrm{f}}$ & $201 \cdot 5^{\mathrm{C}}$ & $2125 \cdot 7^{\mathrm{c}, \mathrm{d}, \mathrm{e}}$ \\
\hline SMI & 8 & $33 \cdot 8^{b, c}$ & $16 \cdot 7^{\mathrm{a}, \mathrm{b}, \mathrm{c}}$ & $23 \cdot 5^{b, c}$ & $78 \cdot 7^{\mathrm{c}, \mathrm{d}}$ & $11 \cdot 2^{\mathrm{c}}$ & 28.7 & $26 \cdot 6$ & $28 \cdot 3^{\mathrm{a}, \mathrm{b}}$ & $60 \cdot 3^{\mathrm{b}, \mathrm{c}}$ & $307 \cdot 9^{b, c}$ & $2403 \cdot 0^{c, d}$ \\
\hline SMI & 24 & $20 \cdot 7^{\mathrm{d}, \mathrm{e}}$ & $11 \cdot 6^{\mathrm{a}, \mathrm{b}, \mathrm{c}}$ & $15 \cdot 1^{\mathrm{c}}$ & $83 \cdot 5^{c, d}$ & $8 \cdot 1^{\mathrm{c}}$ & $15 \cdot 9$ & 49.4 & $14 \cdot 7^{\mathrm{C}}$ & $52 \cdot 3^{\mathrm{b}, \mathrm{c}, \mathrm{d}}$ & $269 \cdot 5^{c}$ & $2476 \cdot 7^{\mathrm{b}, \mathrm{c}}$ \\
\hline $\mathrm{SMI}+\mathrm{AA}$ & 0 & $21 \cdot 2^{\mathrm{c}, \mathrm{d}, \mathrm{e}}$ & $15 \cdot 7^{\mathrm{a}, \mathrm{b}, \mathrm{c}}$ & $23 \cdot 8^{b, c}$ & $80 \cdot 0^{\mathrm{c}, \mathrm{d}}$ & $20 \cdot 4^{b}$ & $5 \cdot 3$ & $34 \cdot 3$ & $10 \cdot 7^{c, d}$ & $22 \cdot 9^{e, f}$ & $234.2^{c}$ & $1704 \cdot 1^{\mathrm{e}}$ \\
\hline $\mathrm{SMI}+\mathrm{AA}$ & 2 & $32 \cdot 9^{\mathrm{a}, \mathrm{b}, \mathrm{c}}$ & $20 \cdot 4^{\mathrm{a}, \mathrm{b}}$ & $29 \cdot 4^{a, b}$ & $71 \cdot 6^{\mathrm{c}, \mathrm{d}}$ & $23 \cdot 8^{b}$ & $12 \cdot 6$ & $14 \cdot 2$ & $14 \cdot 9^{\mathrm{c}}$ & $32 \cdot 0^{\mathrm{d}, \mathrm{e}, \mathrm{f}}$ & $251.9^{c}$ & $1686 \cdot 2^{\mathrm{e}}$ \\
\hline $\mathrm{SMI}+\mathrm{AA}$ & 8 & $36 \cdot 7^{a, b}$ & $20 \cdot 2^{a, b}$ & $31 \cdot 0^{\mathrm{a}, \mathrm{b}}$ & $103 \cdot 9^{b, c}$ & $34 \cdot 5^{a}$ & $24 \cdot 1$ & 29.6 & $32 \cdot 8^{a}$ & $70 \cdot 2^{\mathrm{b}}$ & $382 \cdot 8^{\mathrm{b}}$ & $2158 \cdot 3^{\mathrm{c}, \mathrm{d}, \mathrm{e}}$ \\
\hline $\mathrm{SMI}+\mathrm{AA}$ & 24 & $25 \cdot 0^{\mathrm{b}, \mathrm{c}, \mathrm{d}, \mathrm{e}}$ & $17 \cdot 1^{\mathrm{a}, \mathrm{b}, \mathrm{c}}$ & $25 \cdot 6^{a, b, c}$ & $88 \cdot 0^{\mathrm{b}, \mathrm{c}, \mathrm{d}}$ & $22 \cdot 0^{\mathrm{b}}$ & $10 \cdot 1$ & $61 \cdot 6$ & $22 \cdot 7^{\mathrm{b}}$ & $42 \cdot 6^{\mathrm{c}, \mathrm{d}, \mathrm{e}}$ & $308 \cdot 1^{\mathrm{b}, \mathrm{c}}$ & $1908 \cdot 8^{\mathrm{d}, \mathrm{e}}$ \\
\hline Pooled SEM & & 1.6 & 0.6 & 1.2 & $5 \cdot 8$ & 1.4 & 1.3 & $5 \cdot 1$ & 1.7 & $5 \cdot 2$ & $19 \cdot 2$ & $79 \cdot 2$ \\
\hline ANOVA: $P$ & & & & & & & LG10 & SQRT & & & & \\
\hline D & & $<0.001$ & 0.004 & $<0.001$ & $<0.001$ & $<0.001$ & $<0.001$ & $<0.001$ & $<0.001$ & $<0.001$ & $<0.001$ & $<0.001$ \\
\hline $\mathrm{T}$ & & $<0.001$ & $<0.001$ & $<0.001$ & $<0.001$ & $<0.001$ & $<0.001$ & $<0.001$ & $<0.001$ & $<0.001$ & $<0.001$ & $<0.001$ \\
\hline $\mathrm{D} \times \mathrm{T}$ & & 0.01 & 0.03 & 0.002 & 0.001 & 0.000 & 0.23 & 0.20 & 0.001 & $<0.001$ & $<0.001$ & 0.02 \\
\hline
\end{tabular}

T, time points; TAA, total free amino acids; FM, fishmeal diet; SMI, soyabean meal-incorporated diet; SMI + AA, SMI diet with dietary EAA supplementation; LG10 indicates that data were transformed and statistically analysed with log transforms; SQRT indicates that data were transformed and statistically analysed with square roots; D, diet. a,b,c,d,e,f,g,h Mean values among all treatments within a row with unlike superscript letters were significantly different $(P<0.05)$.

* Treatment means represent the average values for three tanks per treatment and were analysed by two-way ANOVA ( $n 3$ ). Tukey's test was conducted for individual means only if there was a significant interaction $(P<0.05)$.

significant effect on the activation of these nutrient-sensing molecules except for phosphor-eIF $2 \alpha$ in liver and muscle, and ATF4 levels in liver (Fig. 2).

\section{Postprandial modulations of the metabolism by dietary proteins}

Postprandial glucose and TAG reached peak concentration at 2 and 8 h, respectively, after refeeding. However, the peak values of both GLU and TAG were lower in SMI diets (SMI and $\mathrm{SMI}+\mathrm{AA}$ ), compared with those in the FM group (Fig. 3(A)).

The gene expressions of key metabolic enzymes in the liver were determined. In the FM group, the expressions of enzymes for glycolysis ( $G K$ and $P K$ ) (Fig. 3(B)), fatty acid synthesis (SREBP1 and FAS) (Fig. 3(D)) and TAG synthesis (DGAT1 and DGAT2) (Fig. 3(E)) were significantly up-regulated and peaked at $2-8 \mathrm{~h}$ after refeeding. The gene expressions of gluconeogenic enzymes (FBPase and G6Pase) were markedly 
(A)

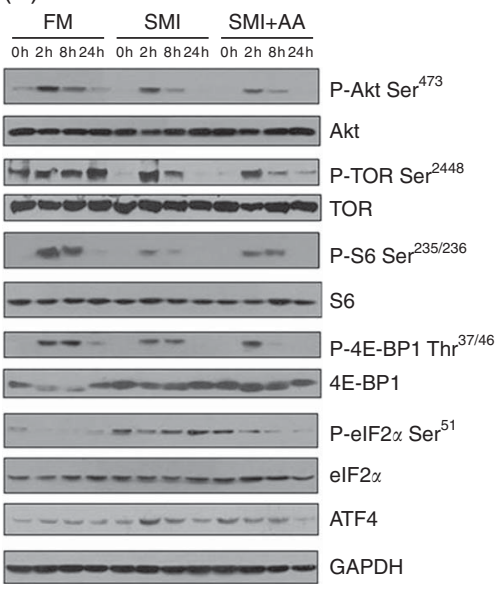

(B)

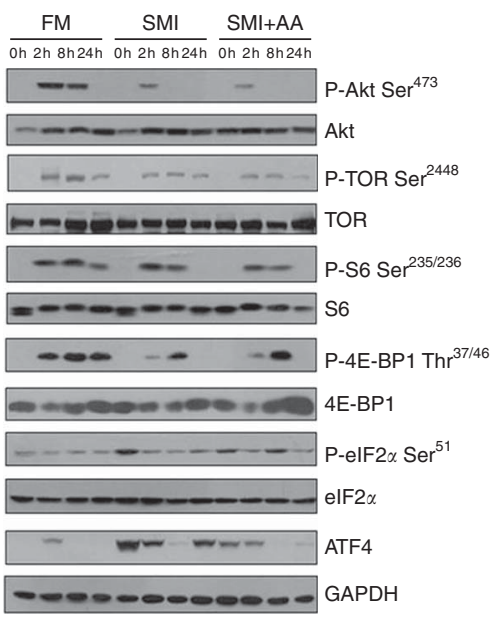

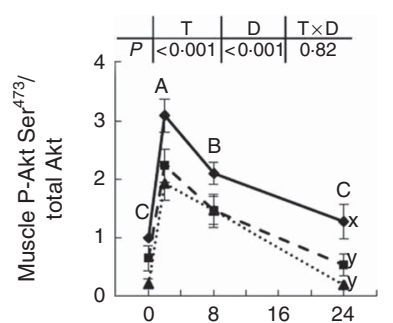
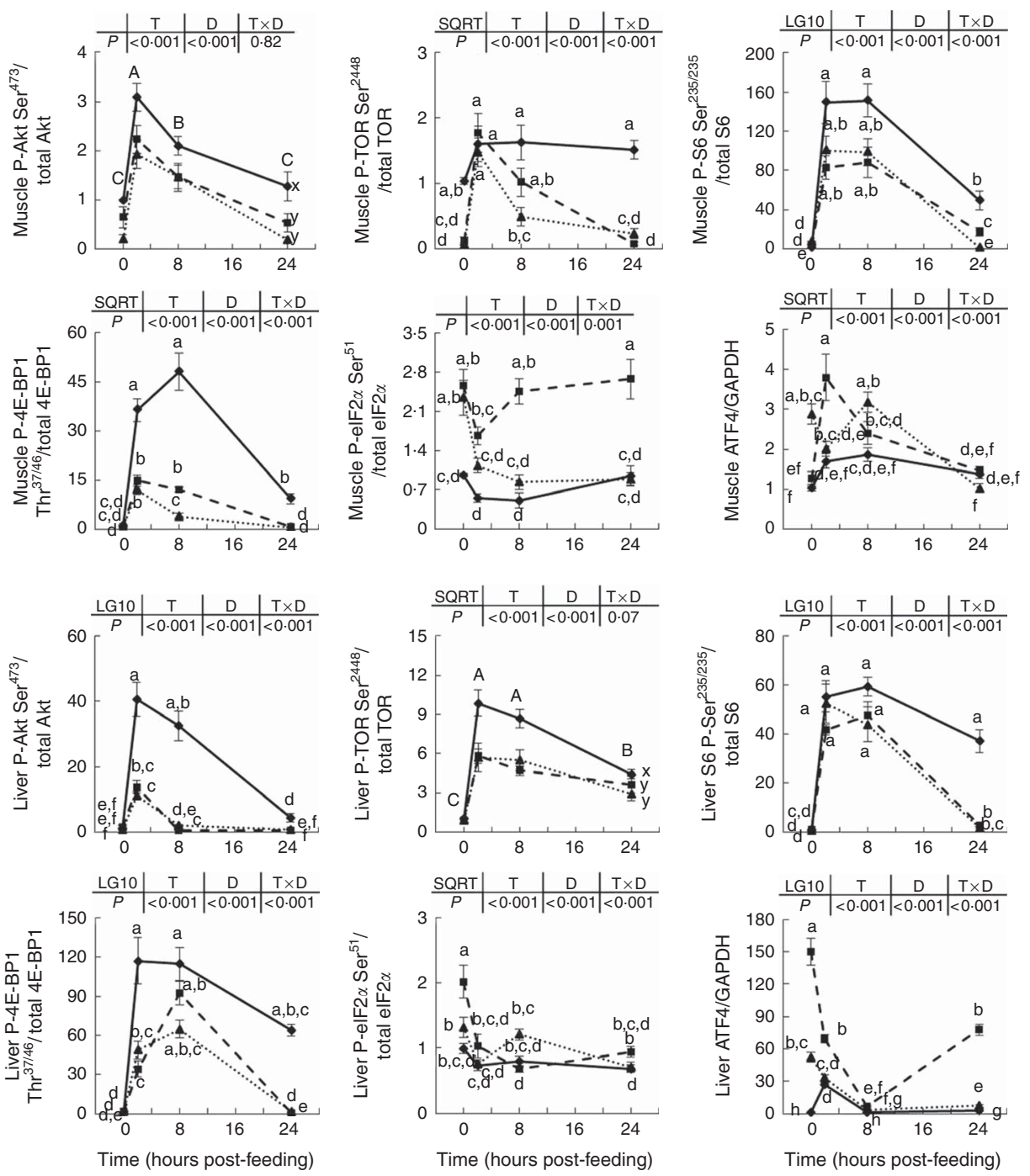

Fig. 2. Dietary modulations of nutrient-sensing responses involving the total and phosphorylation levels of proteins related to target of rapamycin (TOR) and amino acid response signalling pathways in muscle (A) and liver (B). A representative blot is shown from replicated examinations $(n 6)$. Values are means with their standard errors and were analysed by two-way ANOVA followed by Tukey's multiple range test. a,b,c,d,e,f,g,h; $A, B, C ; x, y, z$ Values with unlike letters are significantly different

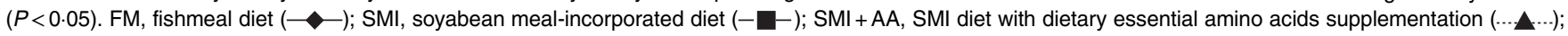
$\mathrm{T}$, time points; D, diets; T $\times \mathrm{D}$, interaction between Tand D; LG10 indicates that data were transformed and statistically analysed with log transforms; Akt, protein kinase B; S6, ribosomal protein S6; 4E-BP1, eukaryotic initiation factor 4E-binding protein 1; elF2a, eukaryotic initiation factor 2a; ATF4, activating transcription factor 4; GAPDH, glyceraldehyde-3-phosphate dehydrogenase (see Fig. 1 legend for details).

down-regulated (Fig. 3(C)). In contrast, these postprandial modulations were not obvious in the two SMI diets with lower transcription levels than those of the FM diet. No significant difference was observed for the gene expression involved in fatty acid oxidation (CPT1A and ACOX1) among different treatments (Fig. 3(F)).

\section{Discussion}

Turbot is an aquaculture species that is highly sensitive to the replacement of dietary FM by plant sources of protein. In previous reports, FM replacements over $20 \%$ using maize gluten meal $^{(27)}$ and over $25 \%$ using soyabean meal concentrate ${ }^{(28)}$ were found to reduce growth rates in turbot. In accordance with these studies, we observed that $45 \%$ dietary FM replacement by soyabean meal reduced growth, feed utilisation and nutrient retention, irrespective of EAA supplementation.

Cellular uptake and transport of peptide and amino acids in the intestine represent a critical step for protein absorption. PepT1 is the major peptide transporter across the intestine brush border membrane in fish ${ }^{(29)}$. We observed that PepT1 expression peaked at $2 \mathrm{~h}$ after refeeding, which is consistent with previous reports stating that the expression of PepT1 was up-regulated by refeeding and down-regulated by fasting in sea bass ${ }^{(30)} . B^{O}$ AT1 and $y^{+}$LAT1 were also identified in fish ${ }^{(31,32)}$ and had a major role in mediating EAA transport across the apical and basolateral sides of the brush border membrane, respectively ${ }^{(23,33)}$. Intestinal $B^{O} A T 1$ was down-regulated, whereas $y^{+} L A T 1$ peaked at $8 \mathrm{~h}$ after refeeding, highlighting their different mechanisms in response to feed ingestion. 

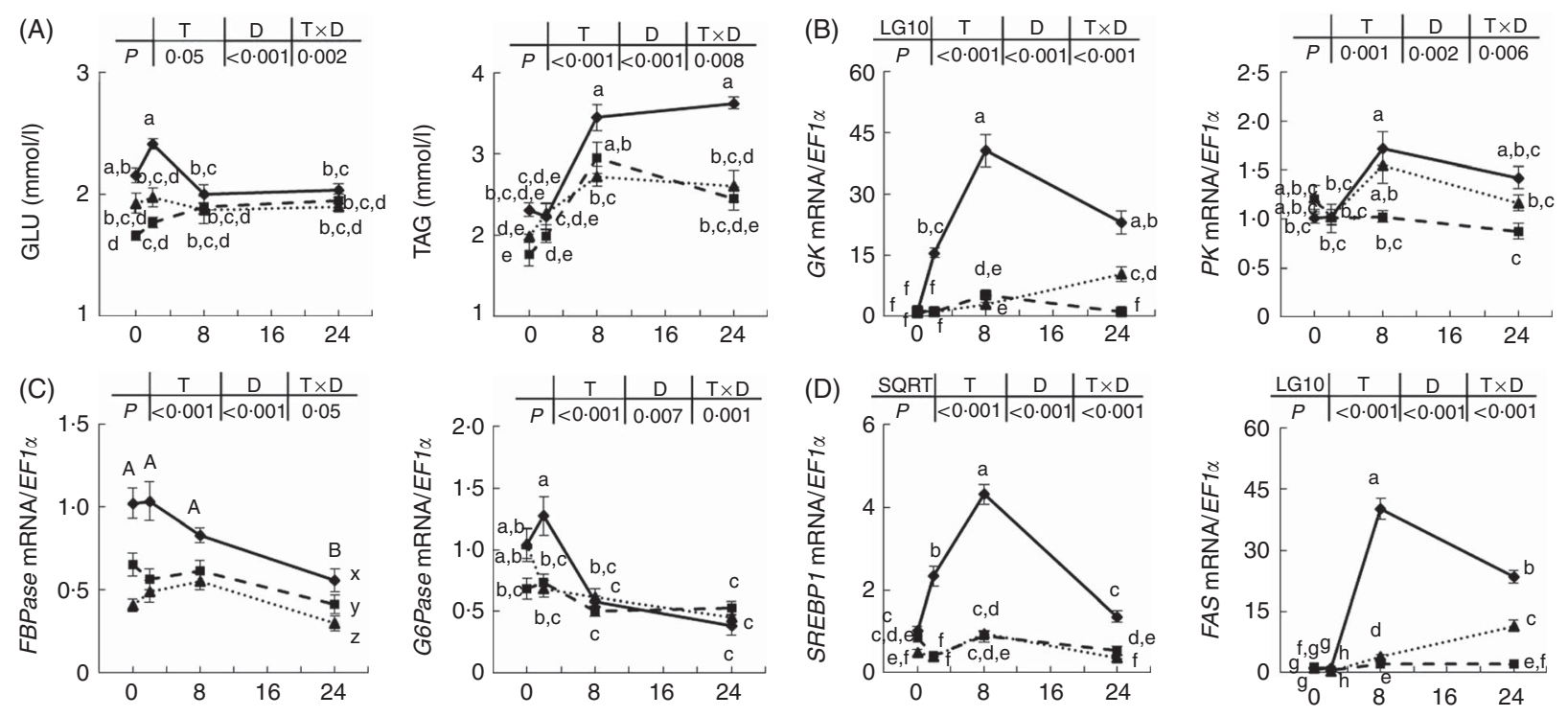

(E) $\quad$\begin{tabular}{c|c|c|c|c|c|} 
SQRT & $T$ & $D$ & $T \times D$ \\
\hline$P$ & $<0.001$ & $<0.001$ & $<0.001$
\end{tabular}
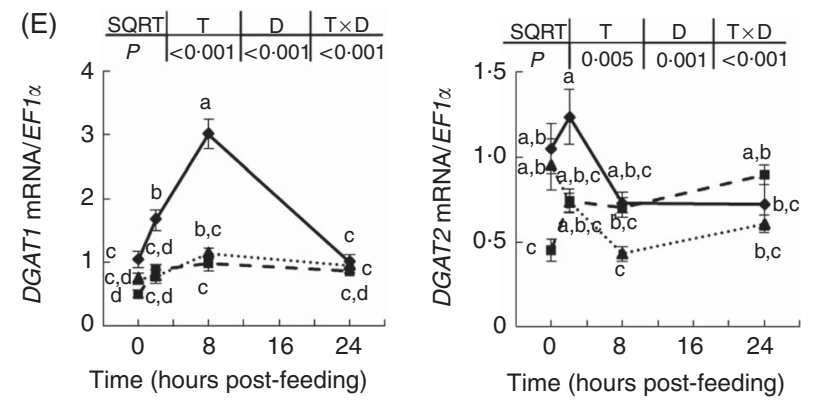

Fig. 3. The dietary modulations of postprandial metabolism. (A) Plasma glucose (GLU) and TAG levels. Expression of selected enzymes involved in (B) glycolysis, (C) gluconeogenesis, (D) lipogenesis, (E) TAG synthesis and (F) fatty acid oxidation were analysed $(n 6)$. Values are means with standard errors and were analysed by

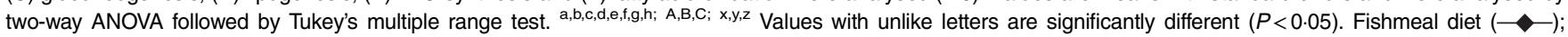
soyabean meal-incorporated diet (- - ); soyabean meal-incorporated diet with dietary essential amino acid supplementation (... . ); GK, glucokinase; EF1a, elongation factor 1a; PK, pyruvate kinase; FBPase, fructose 1,6-bisphosphatase; G6Pase, glucose 6 phosphatase; FAS, fatty acid synthase; SREBP1, sterol regulatory element-binding protein 1; DGAT, diacylglycerol O-acyltransferase homolog; $A C O X 1$, acyl-CoA oxidase 1; CPT1A, carnitine palmitoyltransferase 1 isoforms $\mathrm{A}$ (see Fig. 1 legend for details).

SNAT2, a proven amino acid availability sensor in mammals ${ }^{(34)}$, was down-regulated after refeeding, which is similar to observations from mammalian studies ${ }^{(35)}$. Among the transporters characterised, gene expression of PepT1 and SNAT2 levels was not influenced by different diets. However, $B^{O} A T 1$ and $y^{+} L A T 1$ were less responsive to the SMI diet than the FM diet, suggesting that different protein sources resulted in differential responses of amino acid transporters, which in turn would possibly have influenced amino acid absorption and transport efficiency, accompanied by the change of plasma and muscle free amino acid pools in the present study.

Our results demonstrated that postprandial peak values of plasma free amino acids in circulation occurred $2 \mathrm{~h}$ after refeeding and were transported to muscle in $<8 \mathrm{~h}$. This was similar to observations of rainbow trout ${ }^{(36)}$, but slower than those of rats ${ }^{(37)}$. Postprandial peak values of free amino acids in the SMI group were much lower than in the FM group. Supplementation of EAA to match the amino acid profile of the FM diet in the SMI diets increased postprandial free amino acid levels in plasma, but not in muscle. A similar result was found in turbot after partial FM replacement by maize gluten meal ${ }^{(27)}$. Crystalline amino acids were reported to have a lower retention in muscle compared with protein-bound amino acids ${ }^{(38)}$. This asynchronous amino acid retention may explain the inefficiency of free amino acid supplementation in the SMI diet.

Intracellular sensing of amino acid availability is mediated mainly by two distinct, yet complimentary, pathways - the AAR and the TOR pathways - both of which regulate protein synthesis and metabolism ${ }^{(8,39)}$. TOR activation is the primary driving force for postprandial anabolism ${ }^{(6,7)}$ and is required for postprandial protein synthesis in response to amino acid availability $^{(40)}$. Consistent with findings in mammals ${ }^{(8)}$ and rainbow trout ${ }^{(41)}$, we observed that refeeding activated TOR signalling. A previous study reported that increased amino acid levels enhanced S6 kinase 1 and S6 phosphorylation in rainbow trout primary hepatocytes ${ }^{(13)}$. In the present study, SMI diets reduced the postprandial peak values of free amino acids compared with the FM diet. Accordingly, it reduced the levels and duration of postprandial phosphorylation of TOR, Akt, S6 and 4E-BP1, suggesting a hypoactivated TOR signalling status. However, the SMI diet induced higher eIF2 $\alpha$ phosphorylation and ATF4 levels, indicating hyperactivated AAR signalling and inhibited cellular protein synthesis ${ }^{(39)}$. In particular, AAR enhanced total 4E-BP1 in muscle during fasting and decreased 
its phosphorylation in FM replacement diets, further inhibiting protein translation in cells ${ }^{(42)}$. The combination of hypoactivated TOR signalling and hyperactivated AAR signalling would reduce postprandial protein synthesis ${ }^{(8,39)}$. Chronically, it would lead to lower protein accretion, evidenced by decreased protein retention after 1 month of SMI diet feeding.

TOR and AAR signalling not only control protein synthesis but also regulate metabolic gene expression, both in mammals and in fish $^{(11,26,43,44)}$. In the present study, postprandial increased expressions of key enzymes involved in glycolysis and lipogenesis were associated with the activation of TOR signalling after refeeding, which is consistent with previous reports demonstrating that postprandial activation of hepatic $G K$ and lipogenesis require TOR activation in rainbow trout ${ }^{(26)}$. Furthermore, we observed that SMI diets reduced tissue amino acid concentrations and TOR signalling activities, and suppressed the expression of genes involved in glycolysis and lipogenesis. As previous findings in trout hepatocytes showed that increased amino acid availability effectively up-regulated fatty acid synthetic and glycolytic genes expression in a TORdependent manner ${ }^{(13,45)}$, we presume that SMI diets reduced postprandial tissue amino acid concentration, which in turn suppressed TOR activation and subsequently down-regulated fatty acid synthetic and glycolytic gene expression. However, the soyabean meal-induced increase of eIF $2 \alpha$ phosphorylation and ATF4 levels was associated with down-regulation of hepatic lipogenic gene expression. These results were compatible with previous reports, concerning mice, that activation of the AAR signalling pathway reduced gene expression involved in fatty acid and TAG synthesis, alongside liver TAG and adipose tissue weight ${ }^{(11)}$. Thus, the reduced postprandial lipogenesis gene expression in SMI groups may be related to the combination effects of hypoactivated TOR signalling and hyperactivated AAR signalling. Chronically, it would lead to a lower body fat content of turbot. Therefore, our study provides a reasonable mechanistic explanation for reduced lipogenesis and fat deposition after FM replacement in many studies ${ }^{(46,47)}$.

It has been widely accepted that FM replacement in aquafeeds by plant proteins is limited by factors including low digestibility, imbalanced amino acid profile, anti-nutritional factors, presence or absence of other factors and so on, in plant proteins ${ }^{(1,2,17)}$. However, in fish fewer studies have compared the responses towards different protein sources at the molecular level, nor provided mechanistic explanations of the dietary effects. Our results, together with previous reports ${ }^{(18,26,41)}$, demonstrated that nutrient-sensing networks were conserved in fish, although varied in some aspects, such as the metabolism of glutamine in muscle ${ }^{(48)}$. The present study demonstrated a cascade of sophisticated, but mechanistically connected, responses towards partial FM replacement by soyabean meal in turbot: reduced postprandial influx of free amino acids led to hypoactivated TOR signalling, which in turn reduced protein synthesis and lipogenesis. In contrast, induced AAR responses further aggravated the postprandial anabolism. Such postprandial changes would lead to differences of growth and feed efficiency after long-term feeding. Further understanding the molecular responses of animals to different diets should pave the way for better feed utilisation.

\section{Acknowledgements}

The authors thank the Haiyang fish farm for providing the aquaculture system and animal care direction, and technicians at the South China Agricultural Science and Technology Innovation Center for amino acid analysis guidance.

This work was supported by the National Natural Science Foundation of China (grant number 31222055) and the National Key Basic Research Program of China (grant number 2014CB138602). These funders had no role in the design and analysis of the study, nor in the writing of this article.

G. H. and K. M. designed the study. D. X., F. S., H. Z. and W. X. performed data acquisition and data analysis. G. H. and D. X. wrote the manuscript. All authors read and approved the final manuscript.

The authors declare no conflicts of interest.

\section{Supplementary material}

For supplementary material/s referred to in this article, please visit http://dx.doi.org/doi:10.1017/S0007114515004535

\section{References}

1. Naylor RL, Hardy RW, Bureau DP, et al. (2009) Feeding aquaculture in an era of finite resources. Proc Natl Acad Sci U S A 106, 15103-15110.

2. Hardy RW (2010) Utilization of plant proteins in fish diets: effects of global demand and supplies of fishmeal. Aquacult Res 41, 770-776.

3. Boirie Y, Dangin M, Gachon P, et al. (1997) Slow and fast dietary proteins differently modulate postprandial protein accretion. Proc Natl Acad Sci U S A 94, 14930-14935.

4. Bos C, Metges CC, Gaudichon C, et al. (2003) Postprandial kinetics of dietary amino acids are the main determinant of their metabolism after soy or milk protein ingestion in humans. J Nutr 133, 1308-1315.

5. Frühbeck G (1998) Protein metabolism: slow and fast dietary proteins. Nature 391, 843-845.

6. Kimball SR \& Jefferson LS (2002) Control of protein synthesis by amino acid availability. Curr Opin Clin Nutr Metab Care $\mathbf{5}$, 63-67.

7. Ma XM \& Blenis J (2009) Molecular mechanisms of mTORmediated translational control. Nat Rev Mol Cell Biol 10, 307-318.

8. Laplante M \& Sabatini DM (2012) mTOR signaling in growth control and disease. Cell 149, 274-293.

9. Jewell JL, Russell RC \& Guan KL (2013) Amino acid signalling upstream of mTOR. Nat Rev Mol Cell Biol 14, 133-139.

10. Kilberg MS, Pan YX, Chen H, et al. (2005) Nutritional control of gene expression: how mammalian cells respond to amino acid limitation. Annu Rev Nutr 25, 59-85.

11. Guo F \& Cavener DR (2007) The GCN2 eIF2alpha kinase regulates fatty-acid homeostasis in the liver during deprivation of an essential amino acid. Cell Metab 5, 103-114.

12. Yan L \& Lamb RF (2012) Amino acid sensing and regulation of mTORC1. Semin Cell Dev Biol 23, 621-625.

13. Dai W, Panserat S, Plagnes-Juan E, et al. (2015) Amino acids attenuate insulin action on gluconeogenesis and promote fatty acid biosynthesis via mTORC1 signaling pathway in trout hepatocytes. Cell Physiol Biochem 36, 1084-1100.

14. Lansard M, Panserat S, Plagnes-Juan E, et al. (2011) L-leucine, L-methionine, and L-lysine are involved in the regulation of 
intermediary metabolism-related gene expression in rainbow trout hepatocytes. J Nutr 141, 75-80.

15. Lansard M, Panserat S, Plagnes-Juan E, et al. (2010) Integration of insulin and amino acid signals that regulate hepatic metabolism-related gene expression in rainbow trout: role of TOR. Amino Acids 39, 801-810.

16. Lee J, Cho S, Park S, et al. (2003) Dietary protein requirement for young turbot (Scophthalmus maximus L.). Aquacult Nutr 9. $283-286$.

17. Gatlin DM, Barrows FT, Brown P, et al. (2007) Expanding the utilization of sustainable plant products in aquafeeds: a review. Aquacult Res 38, 551-579.

18. Seiliez I, Panserat S, Lansard M, et al. (2011) Dietary carbohydrate-to-protein ratio affects TOR signaling and metabolism-related gene expression in the liver and muscle of rainbow trout after a single meal. Am J Physiol Regul Integr Comp Physiol 300, 733-743.

19. Liu Y, He G, Wang Q, et al. (2014) Hydroxyproline supplementation on the performances of high plant protein source based diets in turbot (Scophthalmus maximus L.). Aquaculture 433, 476-480.

20. Mente E, Deguara S, Santos MB, et al. (2003) White muscle free amino acid concentrations following feeding a maize gluten dietary protein in Atlantic salmon (Salmo salar L.). Aquaculture 225, 133-147.

21. Zuo R, Ai Q, Mai K, et al. (2012) Effects of dietary $n$-3 highly unsaturated fatty acids on growth, nonspecific immunity, expression of some immune related genes and disease resistance of large yellow croaker (Larmichthys crocea) following natural infestation of parasites (Cryptocaryon irritans). Fish Shellfish Immunol 32, 249-258.

22. Romano A, Barca A, Storelli C, et al. (2014) Teleost fish models in membrane transport research: the PEPT1 (SLC15A1) H+oligopeptide transporter as a case study. J Physiol 592, 881-897.

23. Bröer S (2008) Amino acid transport across mammalian intestinal and renal epithelia. Physiol Rev 88, 249-286.

24. Cunha I, Galante-Oliveira S, Rocha E, et al. (2013) Dynamics of PPARs, fatty acid metabolism genes and lipid classes in eggs and early larvae of a teleost. Comp Biochem Physiol B Biochem Mol Biol 164, 247-258.

25. Wang Q, He G, Mai K, et al. (2015) Fishmeal replacement by mixed plant proteins and maggot meal on growth performance, target of rapamycin signalling and metabolism in juvenile turbot (Scophthalmus maximus L.). Aquacult Nutr (Epublication ahead of print version 14 February 2015).

26. Dai W, Panserat S, Mennigen JA, et al. (2013) Post-prandial regulation of hepatic glucokinase and lipogenesis requires the activation of TORC1 signalling in rainbow trout (Oncorbynchus mykiss). J Exp Biol 216, 4483-4492.

27. Regost C, Arzel J \& Kaushik S (1999) Partial or total replacement of fish meal by corn gluten meal in diet for turbot (Psetta maxima). Aquaculture 180, 99-117.

28. Day O \& GonzÁlez H (2000) Soybean protein concentrate as a protein source for turbot Scophthalmus maximus L. Aquacult Nutr 6, 221-228.

29. Verri T, Romano A, Barca A, et al. (2010) Transport of di- and tripeptides in teleost fish intestine. Aquacult Res 41, 641-653.

30. Terova G, Corà S, Verri T, et al. (2009) Impact of feed availability on PepT1 mRNA expression levels in sea bass (Dicentrarchus labrax). Aquaculture 294, 288-299.

31. Margheritis E, Terova G, Cinquetti R, et al. (2013) Functional properties of a newly cloned fish ortholog of the neutral amino acid transporter $\mathrm{B}^{0} \mathrm{AT} 1$ (SLC6A19). Comp Biochem Physiol A Mol Integr Physiol 166, 285-292.
32. Yang J, Tan Q, Zhu W, et al. (2014) Cloning and molecular characterization of cationic amino acid transporter $\mathrm{y}^{+} \mathrm{LAT} 1 \mathrm{in}$ grass carp (Ctenopharyngodon idellus). Fish Physiol Biochem 40, 93-104.

33. Bröer A, Juelich T, Vanslambrouck JM, et al. (2011) Impaired nutrient signaling and body weight control in a $\mathrm{Na}^{+}$neutral amino acid cotransporter (Slc6a19)-deficient mouse. J Biol Chem 286, 26638-26651.

34. Hyde R, Cwiklinski EL, MacAulay K, et al. (2007) Distinct sensor pathways in the hierarchical control of SNAT2, a putative amino acid transceptor, by amino acid availability. J Biol Chem 282, 19788-19798.

35. Hyde R, Christie G, Litherland G, et al. (2001) Subcellular localization and adaptive up-regulation of the System A (SAT2) amino acid transporter in skeletal-muscle cells and adipocytes. Biochem J 355, 563-568.

36. Karlsson A, Eliason EJ, Mydland LT, et al. (2006) Postprandial changes in plasma free amino acid levels obtained simultaneously from the hepatic portal vein and the dorsal aorta in rainbow trout (Oncorbynchus mykiss). J Exp Biol 209, 4885-4894.

37. Vary TC \& Lynch CJ (2006) Meal feeding enhances formation of eIF4F in skeletal muscle: role of increased eIF4E availability and eIF4G phosphorylation. Am J Physiol Endocrinol Metab 290, 631-642.

38. Berge GE, Lied E \& Espe M (1994) Absorption and incorporation of dietary free and protein bound (U14C)-lysine in Atlantic cod (Gadus morhua). Comp Biochem Physiol A Mol Integr Physiol 109, 681-688.

39. Kilberg MS, Shan J \& Su N (2009) ATF4-dependent transcription mediates signaling of amino acid limitation. Trends Endocrinol Metab 20, 436-443.

40. Dickinson JM \& Rasmussen BB (2011) Essential amino acid sensing, signaling, and transport in the regulation of human muscle protein metabolism. Curr Opin Clin Nutr Metab Care 14, 83-88.

41. Seiliez I, Gabillard JC, Skiba-Cassy S, et al. (2008) An in vivo and in vitro assessment of TOR signaling cascade in rainbow trout (Oncorhynchus mykiss). Am J Physiol Regul Integr Comp Physiol 295, 329-335.

42. Sayano T, Kawakami Y, Kusada W, et al. (2013) L-serine deficiency caused by genetic Phgdh deletion leads to robust induction of 4E-BP1 and subsequent repression of translation initiation in the developing central nervous system. FEBS J 280, 1502-1517.

43. Yecies JL \& Manning BD (2011) Transcriptional control of cellular metabolism by mTOR signaling. Cancer Res $\mathbf{7 1}$, 2815-2820

44. Dibble CC \& Manning BD (2013) Signal integration by mTORC1 coordinates nutrient input with biosynthetic output. Nat Cell Biol 15, 555-564.

45. Lansard M, Panserat S, Plagnes-Juan E, et al. (2010) Integration of insulin and amino acid signals that regulate hepatic metabolism-related gene expression in rainbow trout: role of TOR. Amino Acids 39, 801-810.

46. Dias J, Alvarez M, Arzel J, et al. (2005) Dietary protein source affects lipid metabolism in the European seabass (Dicentrarchus labrax). Comp Biochem Physiol A Mol Integr Physiol 142, 19-31.

47. Deng J, Mai K, Ai Q, et al. (2006) Effects of replacing fish meal with soy protein concentrate on feed intake and growth of juvenile Japanese flounder, Paralichthys olivaceus. Aquaculture 258, 503-513.

48. Ballantyne J (2001) Amino acid metabolism. Fish Physiol 20, 77-107. 